\title{
O ENSINO DE HISTÓRIA NO BRASIL E SEUS PESQUISADORES: BREVES NOTAS SOBRE UMA HERANÇA DE TENSÕES E PROPOSIÇÕES ${ }^{1}$
}

\author{
Letícia Mistura ${ }^{2}$ \\ Flávia Caimi ${ }^{3}$
}

\begin{abstract}
Resumo: Neste estudo, faz-se uma revisão dos percursos do Ensino de História como campo e objeto de estudo, buscando construir uma reflexão sobre as heranças legadas por essa trajetória aos pesquisadores e às propostas atuais do campo. Para tal intento, percorre-se um caminho que parte da história do Instituto Histórico e Geográfico Brasileiro (IHGB) e do Colégio Pedro II, passa pela inauguração da temática do Ensino de História como objeto de reflexão teórica e culmina em uma breve síntese das presentes frentes investigativas que compõem o campo de pesquisa do Ensino de História no Brasil.
\end{abstract}

Palavras-chave: Ensino de História. História do Ensino de História. Historiografia.

\section{THE TEACHING OF HISTORY IN BRAZIL AND ITS RESEARCHERS: BRIEF NOTES ON A LEGACY OF TENSIONS AND PROPOSITIONS}

\begin{abstract}
In this study, we review the paths of History Teaching as a field and object of study, seeking to build a reflection on the legacies inherited by this trajectory to its researchers and the current proposals of the field. For such intent, we trace a path that starts from the history of the Brazilian Historical and Geographical Institute (IHGB) and the Colégio Pedro II, goes through the inauguration of the theme of History Teaching as an object of theoretical reflection and culminates in a brief synthesis of the current investigative fronts that make up the research field of History Teaching in Brazil.

Keywords: History Teaching. History of the teaching of History. Historiography.

\section{L'ENSEIGNEMENT D'HISTOIRE AU BRÉSIL ET SES CHERCHEURS: BRÈVES REMARQUES SUR UN HÉRITAGE DE TENSIONS ET DE PROPOSITIONS.}

Résumé: Dans cette étude, on fait une révision des trajectoires de l'Enseignement d'Histoire en tant que domaine et objet d'étude, en cherchant à construire une réflexion sur les héritages légués par cette trajectoire aux chercheurs et sur les propositions actuelles dans ce domaine. À cet effet, on parcourt par un chemin qui commence par l'histoire de l'Institut Historique et Géographique Brésilien (IHGB) et du Collège Pedro II, ensuite passe par l'inauguration du thème de l'Enseignement d'Histoire comme objet de réflexion théorique et se termine par une brève synthèse des actuels fronts de recherche qui composent le domaine de la recherche de l'Enseignement d'Histoire au Brésil.

Mots clés: Enseignement d'histoire. Histoire de l'enseignement de l'histoire. Historiographie.

\footnotetext{
1 Este artigo é derivado da dissertação de mestrado "Entre tensões e proposições: um estado do conhecimento sobre a aprendizagem histórica no Brasil em dissertações e teses (2005-2018)", que foi realizada com bolsa-auxílio PROSUC/Capes.

${ }^{2}$ Mestre em Educação. Professora da Rede Pública Estadual de Passo Fundo/RS.

${ }^{3}$ Mestre em Educação (UPF), Doutora em Educação (UFRGS) e Pós-Doutora em Educação (FlacsoArgentina). Professora aposentada do Programa de Pós-Graduação em Educação (PPGEdu/MestradoDoutorado) da Universidade de Passo Fundo/RS. Coordenadora do Grupo de Estudos e Pesquisa em Educação (Gespe) e membro do Conselho Editorial da Revista História Hoje.
} 


\section{LA ENSEÑANZA DE LA HISTORIA EN BRASIL Y SUS INVESTIGADORES: BREVES NOTAS SOBRE UN LEGADO DE TENSIONES Y PROPOSICIONES}

Resumen: En este estudio, se realiza una revisión de los caminos de la Enseñanza de la Historia como campo y objeto de estudio, buscando construir una reflexión sobre los legados heredados por esta trayectoria a los investigadores y las propuestas actuales del campo. Para tal, se sigue un camino que parte de la historia del Instituto Histórico y Geográfico Brasileño (IHGB) y del Colégio Pedro II, pasa por la inauguración del tema de la Enseñanza de la Historia como objeto de reflexión teórica y culmina en una breve síntesis de los corrientes frentes de investigación que conforman el campo de investigación de la Enseñanza de la Historia en Brasil.

Palabras-clave: Enseñanza de la Historia. Historia de la enseñanza de la Historia. Historiografía.

\section{Introdução}

A legitimidade do Ensino de História como espaço de interesse investigativo parece ter sido sempre encontrada entre tensões, como ensino versus pesquisa, teoria versus prática, licenciatura versus bacharelado. Relegado ao intermeio de duas grandes áreas, em uma autêntica "zona de fronteira" (MONTEIRO; PENNA, 2011) entre a Educação e a História, o Ensino de História não foi imediatamente entendido como pertinente ao interesse investigativo de nenhuma das áreas, em um jogo mútuo de "batata quente"4 epistemológico, até o final da década de $1970^{5}$. O historiador não deveria perderse em reflexões didáticas; tampouco cabia ao pedagogo enveredar-se pelas especificidades da História como disciplina.

Pode-se atribuir a este fenômeno uma herança da escola metódica (positivismo), que separava as tarefas que cabiam a historiadores e a professores por uma "divisão do trabalho histórico" (PROST, 2015). Era dos historiadores o dever de prover o conhecimento histórico, que assim ficaria à disposição dos professores de História, em dois processos higienicamente distintos. Essa organização do trabalho histórico soa familiar, já que não apenas foi geradora de muitas das dicotomias entre os espaços legítimos ou designados de produção de conhecimento histórico, mas porque

\footnotetext{
${ }^{4}$ Jogo infantil, que, no Brasil, consiste em um círculo de crianças que rodeiam outra criança vendada, enquanto entoam uma cantiga ("Batata quente, batata quente...") e passam entre si uma bola. A bola deve ser passada de criança a criança rapidamente, já que, a qualquer momento, quem está vendado no centro pode gritar "Queimou!", fazendo com que quem estivesse segurando a bola, nesse momento, tome o seu lugar no centro do círculo.

5 Tem-se considerado a década de 1970, de forma geral, como um período de gestação de questionamentos mais profundos, que agitariam os meios de produção reflexiva e crítica, especialmente na pós-graduação, sobre o ensino de História. Trata-se de um marco que acompanha também o crescimento da pesquisa histórica, no Brasil, como atividade profissional. Esse marco diferencia os trabalhos produzidos a partir da década de 1970 dos clássicos estudos sobre o Ensino de História no Brasil entre as décadas de 1930 e 1950 , que fazem parte de outros contextos produtivos. Esses contextos são explorados de forma sistemática, por exemplo, em Fonseca (2003).
} 
recentemente tem-se como consenso que o conhecimento produzido por alunos e professores, em ambientes formais de ensino, e por tantos outros indivíduos e situações, em ambientes não-formais, também diz respeito ao conhecimento histórico, digno e possível de ser estudado como tal.

Cerri (2005) utiliza-se da Geografia como metáfora para significar as fronteiras difusas do campo ocupado pelo conhecimento histórico, refletindo sobre o seu processo de constituição e especialização/fragmentação, processos decorrentes das múltiplas tentativas de domínio, contorno e esquadrinhamento de um grande campo de conhecimento a ser explorado - a Geografia - e faz lembrar sobre a fluidez das ciências, que se conhecem também por meio da compartimentalização, a fim de alcançarem diferentes objetos. Um destes objetos/derivações do campo da História é o Ensino de História - híbrido, fronteiriço, onde "fechar a definição implica também fechar a porta à imensa riqueza interdisciplinar que constitui o campo" (CERRI, 2005, p. 139).

O autor chama a atenção para um aspecto geral sobre esse problema, que também já foi observado por Caimi e Mistura (2019) em outro momento: a necessidade de não perdermos de vista a identidade histórica que os pesquisadores do Ensino de História, autóctones de uma fronteira em que são vistos como estrangeiros, ora de um lado, ora de outro, têm por responsabilidade manter viva e lúcida. Trata-se da consciência e da historicidade do objeto estudado pelo campo e de sua evolução, sob pena de cair-se em repetições e retrabalhos de "novidades" que mantêm essa roupagem há duas décadas.

Pensando na construção da identidade e do lugar de pertencimento do pesquisador do campo do Ensino de História, entendemos que assumir este campo como universo e objeto de pesquisa exige igualmente responsabilizar-se por entendê-lo em sua própria trajetória histórica no Brasil, na composição de si como um campo produtor de investigações e do grupo de vozes e tendências que o permeiam, discussões atravessadas pelos devires da história como disciplina e conhecimento.

Mediante tais preocupações, este texto está estruturado em três partes, buscando alinhavar a localização do pesquisador do Ensino de História entre dois grandes devires contextuais e construir um quadro sintético das tendências atuais do campo, atualmente, por meio de uma breve revisão de textos de pesquisadores que têm se dedicado a discutilo. Primeiramente, delineou-se brevemente alguns caminhos da história do Ensino de História no Brasil, destacando-se dois marcos essenciais em sua trajetória histórica, a saber, a instalação do Colégio Imperial Pedro II - 1837 - e a criação do Instituto Histórico e Geográfico Brasileiro — 1838 - , que alicerçam uma estrutura-herança que 
persegue os caminhos da história ensinada até as décadas finais do século XX, quando se gesta um ambiente específico e propício para a sua discussão crítica, do que provêm questões que contextualizam este estudo. Em um segundo momento, construiu-se o processo de gênese e consolidação do Ensino de História como objeto e campo investigativo, processo que está envolto por diversos tensionamentos. Finalmente, apresentamos algumas sínteses produzidas por pesquisadores do campo do Ensino de História, que têm procurado visualizá-lo, nas últimas duas décadas, em suas propostas e tendências.

\section{A história do Ensino de História no Brasil: trajetória de significado}

Os conhecimentos da História que viriam a ser disciplinarizados em um conjunto sistematizado, organizado e de contornos definíveis estão marcados, mesmo em sua dispersão de origem, pelo manejo e instrumentalização institucional. Da Igreja medieval aos Estados-nação, a trajetória de disciplinarização da história ocidental é pautada por domínios narrativos ${ }^{6}$, por meio dos temas e das abordagens pertinentes às suas naturezas. O mesmo aconteceu com os saberes históricos escolares (FONSECA, 2003).

Como disciplina autônoma e portadora de estatuto científico próprio, a História instituiu-se, em meados do século XIX, junto dos processos de secularização e laicização da sociedade e da constituição dos Estados Nacionais. Então, seu estatuto epistemológico estava calcado em garantir que, pela tentativa de reconstituição exata do passado, via textos e monumentos, o progresso da humanidade (entendida necessariamente como civilização ocidental) fluísse, sem impedimentos, atrasos ou repetição dos "erros" pretéritos. As representações histórico-historiográficas que emergiram desse contexto de ajustes de parâmetros de cientificidade e método ocuparam-se principalmente com os temas da nação, primando pela construção de uma narrativa nacional (DIEHL, 1998; WEHLING, 2001). No Brasil, esse processo acompanha o mesmo métier, que ecoa no Ensino de História e possui dois importantes marcos: a instalação do Colégio Imperial Pedro II e a criação do Instituto Histórico e Geográfico Brasileiro, em 1837 e 1838, respectivamente. Tais marcos constituíram-se como experiências historiográficas e didáticas, legando um conjunto de representações e práticas centrais ao estudo da história

\footnotetext{
${ }^{6}$ É importante destacar que domínios da narrativa histórica ocorrem igualmente após a "conquista" do estatuto científico e disciplinar da História. No entanto, o contexto de secularização impõe uma grande diferença na medida em que permite disputas de domínio entre instituições, movimentos ideológicos e sociais, etc.
} 
do Ensino de História e que, intrincadas, dizem muito sobre a forma como essa disciplina foi produzida institucionalmente, em termos de criação acadêmica, recepção, instrumentalização e gestão.

O processo subjacente a esses dois marcos os precede e os justifica. Na consolidação do Estado Nacional brasileiro, fez-se necessário o esforço pela sistematização e veiculação do perfil da nação, de forma que fossem garantidas identidade externa (às nações europeias, como uma continuidade de sua tradição civilizadora; às demais nações latino-americanas, como um rompimento claro frente às suas naturezas opositoras ao colonizador europeu) e coesão interna (DIEHL, 1998). À concretização deste propósito foi destinada uma instituição específica, o Instituto Histórico e Geográfico Brasileiro (IHGB).

Compunha os desígnios do IHGB, dentre outras, a função de socialização do conhecimento, por meio do mapeamento, delineamento e produção de conhecimento historiográfico sobre a nação Brasil. O sentido desse grande projeto esteve calcado na necessidade de formulação de um passado comum que inserisse a nação do Mundo Novo no rol de continuidade da civilização ocidental europeia, em um enorme território marcado por heterodoxia: a "civilização" chocava-se com os "problemas" (máculas) da escravização de pessoas negras e das grandes populações indígenas. A solução para esses problemas deu-se em uma espécie de "pacto" acerca da produção de conhecimento, consensual e orientado pelo não-rompimento com o passado, interessado pela realidade mestiça brasileira, no mesmo movimento que a mascarava e a higienizava em narrativa.

Este movimento, na trajetória de consolidação e legitimação do IHGB, produziu um dos símbolos da cultura historiográfica brasileira, os chamados mitos "de nacionalidade" ou "conceituais" (o mito da democracia racial e o mito da cordialidade, por exemplo), uma série de narrativas de caráter explicativo e esquemático sobre a formação da nação. Essa composição ajudou a projetar um Brasil definível e reconhecível e, desde sua massiva circulação, foi por inúmeras vezes denunciado em seus diversos "pecados", por variadas produções revisionistas. Portanto, as representações sobre o Brasil fundaram-se hegemônicas, por muito tempo servindo, à guisa de explicações científicas e legítimas, nas mais diversas situações políticas. Essa forma de fazer-se história estava atrelada a uma herança do Iluminismo europeu, especialmente o francês que colonizou (DIEHL, 1998) a vida intelectual brasileira, como ainda será discutido - e o português. A concepção de História subjacente a essas produções compreendia o passado (e aqui, um passado específico, o do europeu ilustrado) como um meio 
pragmático de se obter a clareza para o presente e encaminhar-se o futuro. Tal concepção ainda encontrava na expressão de Cícero, Historia magistra vitae est ("a História é a mestra da vida"), um de seus fundamentos.

O IHGB e seus membros escreviam a História para a veiculação de um tipo específico de conhecimento por uma elite determinada, de acordo com a concepção iluminista sobre a prática de difusão do saber, por esse grupo ilustrado, ao restante da população. Embora fosse uma instituição fundamentalmente acadêmica, foi sagrada pelo Império, operou a tríade Nação-Estado-Coroa para a criação do nexo de nacionalidade que difundiria e viria a ter, cinco anos após a sua fundação, $75 \%$ de seu orçamento fornecido pelo Imperador (DIEHL, 1998, p. 28). Nessas condições, produziram-se as primeiras e icônicas narrativas da história do Brasil, que iriam informar décadas de fundamentos, currículos e práticas de ensino da história.

Como referido anteriormente, há um segundo e importante marco para se compreender a história do Ensino de História no Brasil: a instalação da primeira instituição de ensino seriado da nação, o Colégio Pedro II, concebido como o estabelecimento padrão de ensino secundário do Brasil. Fundado em 1837, o Imperial Colégio Pedro II teria, de acordo com o seu primeiro regulamento, de 1838, e conforme análise trazida no clássico texto de Elza Nadai (1993), o estudo da história em seu currículo. Logo, o ensino de História figurava como componente curricular em todas as oito séries, alternando a sua distribuição ao longo das primeiras décadas do colégio (FONSECA, 2003). As relações da história ensinada com a historiografia eram inauguradas com um peculiar fenômeno: os estudantes aprenderiam e os professores ensinariam por meio de manuais escolares e outros materiais franceses, traduzidos para a língua portuguesa ou, em sua ausência, originais. A presença exemplar francesa — que criou o IHGB à imagem do Instituto Histórico de Paris, fundado quatro anos antes (1834) - na construção do universo intelectual brasileiro foi uma das tônicas de ambos os marcos. A história disponível para estudo, nos manuais franceses, não era a da nação brasileira: estudava-se uma "História universal", essencialmente ocidental, europeia, "civilizadora". A história do Brasil, que ainda não existia em produção historiográfica marcada pelo "selo" do IHGB, era relegada ao papel de apêndice, desestruturada, uma sequência de biografias, nomes, fatos e datas.

$\mathrm{Na}$ República, a identificação com a história europeia permaneceu intensa. Existia, entretanto, a necessidade prática de afirmar a nação em uma nova narrativa, de interesse republicano. Para a consecução desse interesse, há um novo movimento em 
torno da história-historiografia, pautado pela elaboração de símbolos da pátria, facilmente reconhecíveis pela população e de apelo popular. Impulsiona-se uma representação histórica republicana, dando espaço a uma galeria de heróis, postos ou construídos, que alcançam e ultrapassam a escola como espaço de difusão. A partir da consolidação da República, já havia à disposição um considerável volume de produção brasileira sobre a história pátria, tanto em termos de historiografia quanto de manuais didáticos, muitos criados especialmente para uso do/no Colégio Pedro II. Ao longo da República, mudanças políticas acarretariam em ajustes curriculares, deslocando e alocando a história pátria no seu lugar/destino: a formação da identidade nacional.

Conforme Nadai (1993), até 1930 os programas curriculares mantinham-se atrelados aos modelos do Colégio Pedro II $^{7}$, aprovados pela congregação do próprio colégio e dos estabelecimentos estaduais equiparados oficialmente. Com o processo de centralização, nacionalização e uniformização do ensino e a partir das reformas decretadas pelo governo provisório de 1930 (especialmente a Reforma Francisco Campos, de 1931), a equiparação estendeu-se aos estabelecimentos municipais e particulares e os programas começaram a ser expedidos pelo recém-fundado Ministério da Educação e Saúde Pública. É nesse contexto que ocorrem ajustes curriculares baseados em uma proposta política interessada no ensino de história como projeto de nação, primeiramente diluindo a história nacional no mesmo bojo da história universal/geral, e após concedendo-lhe corpo autônomo, de forma a garantir o seu potencial formativo para a consciência patriótica e moral dos jovens brasileiros (FONSECA, 2003). Outras reformas educacionais aconteceriam durante as décadas de 1930 a 1970, em direção aos conteúdos programáticos e sua distribuição na matriz curricular.

Apesar de marcos substanciais em todo o cenário intelectual e educacional do Brasil, como a instalação dos primeiros cursos universitários dedicados à formação de professores e à criação de universidades em São Paulo e no Rio de Janeiro, e o decorrente povoamento de influências francesas e estadunidenses no estudo da história acadêmica, os pressupostos que informavam a prática pedagógica da História pouco se distanciaram da formatação tradicional (a afirmação da formação cívica, da nacionalidade e do devir à nação), ajustando-se aos desígnios de instrumentalização ditados pela esfera políticogovernamental. Podemos observar uma continuidade de tom nos prefácios e introduções

\footnotetext{
${ }^{7}$ Após a Proclamação da República (1989), o Colégio Pedro II foi renomeado por duas vezes antes de voltar ao seu nome original, em 1911. Foi inicialmente rebatizado "Instituto Nacional de Instrução Secundária" e, após, “Ginásio Nacional”. O clássico livro de Doria (1997), dentre outros, tematiza este processo.
} 
da produção didática para o Ensino de História. João Ribeiro, em seu "História do Brasil", de 1935, ao fazer breves comentários sobre a sua escolha de finalização para a narrativa histórica do livro, justifica-se "Não passei além da proclamação da República (1889); os sucessos são ainda do dia de hoje e seria prematuro julga-los em livro destinado ao esquecimento das paixões do presente e à glorificação da nossa historia." (p. 20). ${ }^{8} \mathrm{Na}$ apresentação do primeiro volume da "História do Brasil" de Rozendo Sampaio Garcia e Maxim T. Carone (1946), escreve Astrogildo de Mello, professor da Universidade de São Paulo, que supervisionou a produção da obra:

Foi nossa preocupação no traçado do presente compêndio o objetivo de apresentar em lições claras e concisas os fatos da História do Brasil de acôrdo com o nível mental dos jovens a que se destinam. Possam estas páginas alcançar esta finalidade e estaremos fartamente compensados do esfôrço que dispendemos em pról da formação cívica da mocidade de nossa terra. (GARCIA; CARONE, 1946, p. 7).

Na obra de Vicente Tapajós, de 1954, "História do Brasil", Alfredina de Paiva e Sousa, professora-chefe do curso de formação do professor primário do Instituto de Educação do Rio de Janeiro, assevera, em prefácio:

Quando se trata da história pátria há, ainda, a necessidade de fazer com que um saio sôpro de nacionalismo agite as narrativas. Nenhum acontecimento pátrio poderá ser apresentado de modo frio e impassível: das vitórias e das derrotas, das facilidades e dos empecilhos deve brotar um fecundo sentimento de amor nacional. (TAPAJÓS, 1954, p. 11).

Os autores R. Haddock Lobo (1967) e Brasil Bandecchi (1971), em suas histórias do Brasil para os ciclos colegial e ginasial, trazem a perspectiva do passado orientador do presente, de forma orgânica e exemplar, respectivamente:

Aos brasileiros cabem motivos de sobra para exaltar as qualidades de seus antepassados, que lhes legaram um dos mais extensos países do mundo. Não teria sido possível, na verdade, conquistar tão impressionante vastidão territorial sem muito dinamismo, muito espírito de iniciativa e acentuada capacidade de luta e sacrifício. [...] não podemos participar conscientemente da vida pública do Brasil, e nela influir com possibilidades de acêrto, se ignorarmos os antecedentes da realidade contemporânea, se não possuirmos uma visão bastante lúcida das diretrizes e acontecimentos cruciais que constituem a História Pátria. (LOBO, 1967, p. 11).

Uma aula de História, além de ser uma aula que penetra no passado e o traz para o presente, é uma aula de civismo, de amor da pátria. E os grandes exemplos do passado, a luta dos sábios, dos heróis, dos santos, dos intelectuais, de todos os

\footnotetext{
${ }^{8}$ Manteve-se a grafia original para todas as citações documentais.
} 
que constituem um povo, são exemplos dos quais se deve tirar o que de melhor existe [...].”. (BANDECCHI, 1971, p. 7).

Visualiza-se, por meio desses excertos narrativos da produção de livros escolares no curso de algumas décadas, a formatação de um lugar específico e direcionado ao ensino de História, que permanece em um centro "duro" de pressupostos discursivos, esfera maleável apenas nas mãos do domínio político. Vimos o papel decisivo do Império no início da trajetória da escolarização formal oficial, no Brasil, as transformações decorrentes da proclamação da República e o impacto das políticas do governo provisório de Vargas, em 1930 — todos os "projetos de nação" aportam na História, e numa história específica, de veiculação escolar, o meio de instrução para a formação do corpo nacional desejado - tanto para uma elite, que deve assumir seu papel eventual como diretora da pátria quanto, ao longo do tempo, para a população em geral.

Também durante o Regime Militar ${ }^{9}$ (1964-1985) a história escolar é modelada ao sabor conjuntural, tendo sido, em diversos estados do país, eliminada do currículo do ensino fundamental, sendo substituída, junto à geografia, pelos “Estudos Sociais". Apesar de e juntamente com o peso da tensão entre a emergência da escrita da história marxista e o poder da censura que marca o período, há medidas políticas concernindo à formação docente: as licenciaturas são encurtadas e a atuação dos professores é vigiada. A história dita tradicional, já predominante, serve bem ao regime, que a reforça em termos pedagógicos, estabelecendo as narrativas mortas, os mitos conceituais, as periodizações clássicas, a cronologia linear e progressiva, o estudo dos grandes homens. Ao espelho dos dirigentes da nação, também o ensino devia ser autoritário; o professor representava a autoridade, concedida politicamente, do conhecimento. Da crise do Regime Militar à Redemocratização (décadas de 1970 e 1980), o ensino de História foi moralizado e higienizado, como forma de controlar seus possíveis impulsos de interpretação, análise ou resistência à conjuntura.

O movimento de abertura das perspectivas do campo do Ensino de História acompanha as tendências interpretativas vigentes pela historiografia da época, problematizando e questionando uma história positivista e de modelos frente a uma perspectiva marxista e de modelos, em que as diferenças históricas nas relações sociais

\footnotetext{
${ }^{9}$ Considera-se pertinente o atual debate, encabeçado pelos historiadores Carlos Fico e Daniel Aarão Reis acerca da terminologia a ser utilizada para denominar o período em que, após um golpe, os militares assumiram, por 21 anos, os destinos da nação brasileira. Não sendo viável entrar no mérito interno da discussão, optou-se por denominar o período "regime" militar, já que a designação "militar" representa de forma acurada o regime político da época, em que os dirigentes da nação foram, de fato, somente militares.
} 
do Brasil foram admitidas e a abertura se deu por meio das noções globais do marxismo, a luta de classes e os sistemas de produção. Ao final da década de 1980 e no início dos anos 1990, as movimentações recentes na escrita da história na Europa chegam ao Brasil, proporcionando um relacionamento mais consistente com a produção historiográfica e uma revisitação ao currículo. Há a preocupação de que conteúdos históricos do ensino acompanhem as tendências contemporâneas da escrita da história; a demanda por materiais que não estivessem vinculados a nenhum dos dois modelos anteriormente vigentes se fazia presente. Políticas públicas como o Programa Nacional do Livro Didático, por meio de avaliação prévia da qualidade das obras destinadas ao uso escolar (o Guia Nacional do Livro Didático, desde 1993) e os Parâmetros Curriculares Nacionais (PCNs), procuraram incorporar sensivelmente estas tendências, porém herdam um “edifício" do século XIX (FONSECA, 2003) difícil de ser derrubado e caem na armadilha de "justaposição" de paradigmas antigos e novos (CAIMI, 1999b), em um ecletismo paradigmático. Em situação de ecletismo, perdem-se as condições de se empenharem rupturas necessárias, tanto no que diz respeito a perspectivas de prática pedagógica quanto de natureza teórica. ${ }^{10}$

Outro processo, presente desde o início do século XX, envolve-se e dialoga com a diacronia da cultura historiográfica e do ensino de História brasileiros: a gestação de um contexto produtivo para as reflexões sobre o Ensino de História. Ao adentrar-se, um século mais tarde, num campo de produção científica consolidado, constituído de vigorosas linhas investigativas, é pertinente compreender como esse espaço foi construído, desenvolvido e vetorizado.

\section{Entre tensões e proposições: ensino, pesquisa e níveis de estruturação do discurso histórico}

As primeiras produções que erigiram o ensino da disciplina de História como objeto deram-se, como já mencionado, no início do século XX, com trabalhos que se dirigiam aos professores, na condição de manuais de prática de ensino ou "balanços" da produção didática sobre a História, como os de Jonathas Serrano (1935), Murilo Mendes (1935) e Guy de Hollanda (1957). Naquele contexto, fizeram parte da constituição do corpo disciplinar e escolar da História, consolidada em permanência, exposição e

\footnotetext{
${ }^{10}$ Em Silva e Fonseca (2010), encontra-se uma análise compreensiva do Ensino de História no Brasil, articulando-se tradições de discursos, políticas públicas, currículos e experiências escolares.
} 
expressividade nos currículos ${ }^{11}$. Tem-se admitido as reflexões de Emília Viotti da Costa, publicadas em 1957, na Revista de História da Universidade de São Paulo, sob a seção "Questões Pedagógicas", como inaugurais das reflexões teóricas sobre o Ensino de História. Nas décadas de 1960 e 1970, entretanto, a produção dedicada a este fim encontrou expressividade em um gênero estreito de reflexão, os chamados "relatos de experiência”, que veiculavam narrativas de caráter biográfico, individual e experimental, deslocadas da tônica de criticidade e reflexividade que caracteriza a abordagem das práticas de ensino como objeto.

O Ensino de História emerge como objeto de pesquisa inserido no contexto da Redemocratização, impulsionando o movimento crítico que se tornou signo da reflexão sobre as práticas de ensino da história na década de 1980. É entre as décadas de 1980 e 1990 que viria a gestar-se um espaço de produção para os interessados em refletir, analisar e investigar o Ensino de História (FONSECA, 1989/1990; ZAMBONI, 2000/2001, 2009; COSTA, OLIVEIRA, 2007). Durante aquelas décadas acontecem as primeiras edições dos eventos científicos mais importantes dessa comunidade de pesquisadores, o Encontro Nacional Perspectivas do Ensino de História e o Encontro Nacional de Pesquisadores em Ensino de História; a Associação Nacional de História (ANPUH) passa a admitir como sócios professores de outros níveis de ensino, que não apenas do ensino superior; e o principal periódico da mesma Associação, a Revista Brasileira de História, passa a ter um espaço destinado a publicações sobre o Ensino de História.

Os percursos que encaminharam a condição do Ensino de História como objeto de reflexão intelectual, especialmente nas últimas quatro décadas, estiveram continuamente circunscritos por tensões. Estas tensões podem ser representadas por dois grandes contextos em diacronia: 1) a histórica dicotomia que separou, por muito tempo, as dimensões de "ensino" e "pesquisa", no ensino superior e na pós-graduação brasileiros, e 2) a extensa discussão epistemológica em torno da qual a disciplina histórica se tem revolvido - e as concepções de "ensino de História" que derivam dessas discussões.

Desses contextos deságuam tensões como universidade $\mathrm{x}$ escola, ensino $\mathrm{x}$ pesquisa, teoria x prática, história x memória, história ensinada x aprendida $\mathrm{x}$ vivida, ensino x aprendizagem, história conhecimento x escolar x cotidiana (CARRETERO, 2010). Do esforço empreendido pelo movimento de muitos por tematizá-las e debruçarse sobre elas em busca de interpretação, compreensão e discussão, emergiram diferentes

${ }^{11}$ Argumento de Itamar Freitas (2006), ao tratar da "primazia das humanidades", em sua tese "A pedagogia da história de Jonathas Serrano para o ensino secundário brasileiro (1913-1935)". 
frentes de pesquisa que povoam o que hoje compreendemos como um "campo" que perfaz os interesses investigativos acerca do ensino e da aprendizagem da História. Facetas de um "nó" que amalgama as problemáticas circundantes do ensino e da aprendizagem da História, como campo investigativo e realidade escolar, é necessário enredar-se nestas tensões, expressas em dois momentos, para que se possa aproximar do que significa e demanda a preocupação contemporânea em pesquisar, ensinar, aprender e viver a história, especialmente quando localizadas em uma especificidade temporal-espacial, o Brasil do século XXI.

Durante muito tempo, as práticas que separavam os universos do "ensino" e da "pesquisa" estiveram muito mais cindidas do que relacionadas. A dimensão dos problemas de ensino ${ }^{12}$ não comportava as especificidades de cada disciplina, mesmo internamente aos cursos de Licenciatura, nas chamadas "disciplinas pedagógicas" (geralmente ministradas por profissionais das Faculdades ou Centros de Educação) nem isto era reivindicado pela própria disciplina de História, como veremos a seguir. Acreditava-se que para ensinar História, bastava que se soubesse a "história". As pesquisas produzidas a partir dos programas de pós-graduação em Educação também não comportavam de forma legítima o interesse de se investigar sobre os problemas gerados pela experiência de escolarização dos saberes produzidos pela ciência histórica. Ali, em certa medida, acreditava-se que, para ensinar História, bastava saber ensinar.

A manifestação, durante as décadas de 1980 e 1990, de novas frentes de pesquisa no Brasil, sumarizadas, respectivamente, pela crítica das dicotomias entre o conhecimento histórico acadêmico e o escolar e pela formulação de novas propostas metodológicas envolvendo diferentes fontes e linguagens, decorre da interação entre as insuficiências de ambos os espaços - o epistemológico e o institucional - em responder às demandas de uma sociedade em processo de redemocratização. Nesse sentido, buscouse - um movimento de natureza perene - aproximar a escola da universidade, o que implicou o enfrentamento da imposição assimétrica entre a História dita "conhecimento", produzida nos meios científicos, e a versão de "história" que existia efetivamente nas escolas, a história escolar.

Desta profunda dicotomia entre dois lugares de legítima produção de conhecimento, transparece uma grande controvérsia, tocante à dificuldade de

${ }^{12}$ É interessante observar que a primeira produção dedicada à reflexão sobre o objeto ensino de história no Brasil, o texto de Emília Viotti da Costa, é publicado na Revista Brasileira de História sob a seção "Questões pedagógicas", dada a inexistência de uma seção específica às problemáticas do Ensino de História. 
circunscrição dessas "histórias" sob a compreensão de que ambas são, por natureza, versões, construtos ou registros, e não a história em si, enrustida em instrumento narrativo ou pedagógico. A história, como muito perspicazmente escreve Paul Veyne (1998), do centro das discussões sobre a natureza do conhecimento histórico dos anos 1970, não existe. O pesquisador espanhol Mario Carretero (2010) sinaliza este confronto entre registros do passado, imbuídos em uma das facetas da metamorfa "história", quando põe em discussão as representações do passado que convivem na construção/no desenvolvimento dos sujeitos. Ao localizar três "níveis de estruturação de discursos" (CARRETERO, 2010, p. 34) que contribuem para a formação de "algo-histórico" em todas as pessoas cuja escolarização teve como passado histórico a construção de um sistema institucional escolar sob um Estado-nação, especialmente nos países iberoamericanos, o autor focaliza as particularidades da História como conhecimento disciplinar (história conhecimento), como memória coletiva (história cotidiana) e como saber escolar (história escolar). Assim, avança na compreensão sobre quais seriam/são/podem ser os objetivos do ensino de História em um século XXI imerso nas consequências da globalização, e sobre quais devires-problemas a sua articulação está submetida.

A história conhecimento é, desde o século XIX, segundo Carretero (2010, p. 37), "uma ferramenta cultural organizadora da experiência temporal da vida", acrescentandolhe "com capacidade de fixar identidades". A concepção de "história" que decorre da formalização da disciplina histórica no século XIX estrutura-se durante o século XX confrontada em si mesma. O conhecimento histórico produzido pelo século XIX não é o mesmo desejado pelos novecentos. A construção identitária, objetivada pela e herdeira da narrativa da formação dos Estados Nacionais ibero-americanos é insuficiente defronte a uma proposta mais aproximada de uma compreensão disciplinar da História como conhecimento produzido contextualmente, intencionalmente. Questionando a si mesma e aos dedicados a pensá-la e a escrevê-la em teoria e método, a História como ciência entra em um conflito existencial, epistêmico. Desse conflito eflui a tensão entre história conhecimento e história cotidiana - ou história e memória -, sobre a qual os historiadores dos dois últimos séculos foram produtores de inúmeras elaborações.

A história-devir (cotidiana), de acordo com Carretero (2010), a que se propaga em legado, a que se carrega geracionalmente, não pode ou deve ser ignorada. É no seu interior que se produzem estratégias de valoração do passado, que geralmente chegam aos nossos olhos, apropriáveis pelos sentidos, que permitem que sejam compreendidas as dinâmicas 
de seleção e organização, lembrança e esquecimento, elaboradas pelos grupos sociais. Ainda que a fonte primária de produção da história cotidiana sejam as experiências sociais, também dela participam derivações da história escolar e da história conhecimento, fundidas em um mesmo meio, operante cotidianamente para a construção de uma memória coletiva, ou seja, a articulação de enunciados sobre o passado, como também é entendida por Maurice Halbwachs (2006). Para Carretero (2010, p. 36), a história cotidiana "[...] ressignifica de modo informal parte do 'saber ensinado' e parte do "saber sabido", e o utiliza para interpretar o presente sob o nome de 'atualidade"”.

A construção de uma memória coletiva permite elaborar e digerir os conflitos vividos em comum, tornando possível a articulação de narrativas sobre como vivem os grupos sociais, como organizam-se e orientam-se, elaborando ferramentas de coesão social e de formulação/revisão de valores úteis ao presente e ao futuro. Sendo uma importante salvaguarda identitária e de orientação temporal-espacial, não pode ser demovida. Conforme Carretero (2010, p. 34), não somente se aprende a memória coletiva, mas também ela se "encarna" em cada indivíduo, em identidade e legitimidade, "obrigando-os a considerar suas inter-relações ao subjetivar e instituir a comunidade em sua experiência de vida". A história cotidiana pode, no entanto, ser instrumentalizada e utilizada pragmaticamente, de acordo com a conveniência/pertinência de suas versões para garantir-se posições de poder no presente (CARRETERO, 2010, p. 33), como mostra o estudo de Laville (1999). Por meio de exemplos ilustrativos de vários países, o autor fala sobre o espectro de acirramento político a que o ensino de História é submetido, traduzido em "guerras de narrativas" - da discussão do ensino de seu conteúdo e de seu acesso pelos estudantes nas instituições escolares. Dentre elas, intensos embates entre governos-situação, profissionais da História e a população, no intuito de manter uma ordem de coisas estabelecida; a necessidade de reescrita da história nacional a partir de dinâmicas deliberadas de lembrança-esquecimento, quando da troca de um regime político por outro, ou a reescrita da história atuando como forma de luta pela identidade de um grupo social ou por uma narrativa que corresponda aos anseios da população em um novo regime político.

A história conhecimento que informou a história escolar foi, em seus princípios, a veiculada pela produção historiográfica do século XIX, a história da nação produzida no contexto de consolidação do Estado nacional. Ambas se entrelaçam consanguineamente: o ensino da história nacional, especialmente sob a égide da escolarização obrigatória e gratuita, configurou-se numa espécie de aparato ideológico do 
Estado, articulando eficientemente a transição das identidades universais às nacionais (CARRETERO, 2010). A escola e, nela, a aula de História, têm sido, desde o século XIX, um espaço privilegiado de circulação e consumo de versões históricas específicas para os cidadãos em desenvolvimento, em um formato de fazer-sentido estável, ao instaurar "perguntas que poderiam ser respondidas de uma só maneira", delimitando, simultaneamente, “o auditório e o repertório” (CARRETERO, 2010, p. 18-19).

A versão de história corporifica-se, no âmbito da escola, na organização de saberes históricos em sequências cronológicas, políticas, conceituais, taxonômicas, que passam a compor um corpo curricular, um refúgio firme e impenetrável para uma identidade nacional e umbilical. Como todas as versões que competem pela legitimidade de representação e narrativa do passado, a história escolar funciona na base de um relato único, amplamente difundido, por décadas a fio. Ao conciliar o discurso oficial a uma experiência de passado comum, o currículo da História fornece "uma importante carga emocional destinada a criar identificação [...] e um sentimento de lealdade e pertencimento, fortalecido pelo uso dos símbolos pátrios, os ícones e os hinos da rotina escolar" (CARRETERO, 2010, p. 36). Visualizamos isso, com efeito, nos textos e ilustrações dos manuais didáticos destinados aos estudantes (ABUD, 1998). Quando as formas de ensinar e aprender História são confrontadas com os questionamentos que circundam o saber disciplinar de referência, ao longo do século XX, emergem as tensões entre ambos. Então, a história disciplinar (conhecimento), como já vimos, enfrentava uma crise de validade e legitimidade de seus modelos explicativos, que punha em xeque seu próprio estatuto de saber, sua epistemologia - era necessário produzir respostas aos que questionam a possibilidade e a veracidade do conhecimento histórico e, como diz Chartier (2014), “abandonar sua certeza de que não havia lacuna entre o passado, tal como realmente o era, e a explicação histórica que o interpretava". Especialmente após a chamada "virada linguística ${ }^{13}$ ", na década de 1970, espalhou-se o mal-estar no campo da História, cuja forma narrativa passou a ser questionada, em termos de sua composição e cientificidade. Muitas respostas foram elaboradas desde então. Aos que defendem a História como conhecimento possível sobre o tempo (e sobre o tempo histórico, tempo-

\footnotetext{
${ }^{13}$ Importante movimento do século XX, que inaugurou o desenvolvimento, na ciência ocidental, de estudos sobre as relações entre linguagem e interpretação/construção da realidade, por meio do postulado de que a linguagem não seria mera expressão de pensamento, mas sim sua constituinte - e, portanto, constituinte dos limites da exploração do real pela mente. A virada linguística acabou por impulsionar estudos que focalizavam a linguagem e alavancou a filosofia da linguagem ao longo do século $\mathrm{XX}$, com efeitos até os dias atuais e que provocaram tensões em diversas áreas do conhecimento, inclusive na História.
} 
significado, em duas dimensões próprias), as dinâmicas entre relato e discurso da construção histórica não exclui dela sua legitimidade, rigor e critérios de cientificidade - é preciso considerar todos os elementos que compõem uma representação do passado, inclusive quem a escreve. A História conhecimento precisou reestruturar-se epistemologicamente.

Chegaram ao Brasil, por meio da crise epistemológica da História como conhecimento, novas concepções sobre o papel e o trabalho do historiador, a relação com as fontes e seu tratamento, com o campo disciplinar das ciências humanas e sociais, bem como o interesse crescente por uma diversidade de temas e sujeitos, anteriormente relegados. O conhecimento histórico passou a assumir um diferente papel na esfera social e cultural, na medida em que foi sendo reivindicado como modo de interpretação da realidade, não mais pragmaticamente, mas pela racionalização de seus métodos. Logo, a natureza de relato único e fragmentário da história escolar não mais corresponde à legitimidade de um saber que tem como referência as novas formas de produzir conhecimento histórico disciplinarmente. As funções da história escolar também entram em crise, uma vez que as rupturas que necessita empenhar lidam com lugares institucionais complexos, produtores de uma rede de relações de poder e de restrições, onde também se produz uma outra ordem de saber (o saber histórico escolar), cuja natureza é estranha. Carretero (2010) avalia que, assim, a entrada de outras vozes no cenário do Ensino de História torna-se difícil: a tensão reside não somente no aceite de novas versões ou interpretações históricas, mas na responsabilidade de reconhecê-las como espaços de novas construções de sentido ou de operações cognitivas em níveis mais complexos do que os das simplistas transmissão-assimilação, pergunta-resposta, causaconsequência, memorização - como o relato histórico apresentado na escola anteriormente impunha. $\mathrm{O}$ autor questiona: é a tensão entre história escolar e história conhecimento realmente uma contradição entre saberes que não mais dialogam ou tratase de uma articulação entre história, escola e nação da qual ainda não podemos prescindir? Desde o século XX até a atualidade, em muitos países de todo o globo e como anteriormente comentado, o Ensino de História entrou em pauta de forma inflamada (LAVILLE, 1999; CARRETERO, 2010). Para Carretero, as preocupações emergem da necessidade de revisão das histórias nacionais e locais, produzindo reconsiderações do passado. Alguns efeitos são visualizáveis: 
a) a busca de uma relação significativa entre a representação do passado e da identidade, seja nacional, local ou cultural; b) a demanda de histórias menos míticas e mais objetivas; c) a necessidade de elaboração dos conflitos do passado com vistas a realizar projetos futuros, como é o caso da reinterpretação dos conflitos nacionais europeus em nome de um futuro comum; d) a ainda muito incipiente utilidade de gerar uma comparação entre histórias alternativas de um mesmo passado. (CARRETERO, 2010, p. 23-24).

No Brasil, não tem sido diferente: as perguntas emergentes do século XXI estão imersas na condição de um olhar quase compulsório para a tensão entre a história escolar, a história cotidiana/memória coletiva e a história conhecimento, enfrentando um diálogo atribulado - pelas demandas interpretativas que surgem e se multiplicam a cada segundo do presente; pelo esforço em mapear gêneses e discursos relacionados às demandas; pela urgência da sociedade em depositar expectativas de futuro num complexo sistema, compreendido pelo termo "educação"; pela dificuldade de abrir clareiras em uma tensão cuja própria natureza é o intrincamento. Vemos a manifestação dessa tensão nas temáticas perseguidas pelas pesquisas acerca do Ensino de História, como a superação de práticas pedagógicas baseadas na passividade e na memorização dos estudantes; pelo enfrentamento de novos significados para as relações entre estudantes e professores; a formação de professores; problemáticas envolvendo a cultura escolar; o uso de novas linguagens e tecnologias em sala de aula; a produção, difusão e usos dos livros didáticos de história, dentre outras, permeadas por tons de urgência e esperança.

A grande tensão entre história conhecimento, história cotidiana e história escolar guarda, em si, a cronologia e o confronto de poder entre esses níveis de estruturação do discurso histórico. Mais do que a disputa entre formas de fazer-se, ler-se e viver-se a história, esta tensão põe em xeque formas diversas de sentido de história, que convivem, conversam e se enredam no desenvolvimento humano, dando forma a diferentes domínios da subjetividade e os envolvendo mútua e progressivamente (CARRETERO, 2010). Como escreve Carretero (2010, p. 51):

o mais substancial não está na pureza das taxonomias [os "tipos" de discursos históricos], mas sim nos espaços de contaminação, zonas de alto tráfico as quais nos levam a entender que o que torna o conceito de história tão escorregadio é precisamente sua vitalidade, o mesmo que o faz pulsar em nossas mãos cada vez que tentamos apreendê-lo.

As práticas de ensino e aprendizagem da história se movimentam em problemáticas exatamente pelo dinamismo entre as "zonas de contaminação", e seu principal produto tem sido, como assinala a intensidade de produção no campo do Ensino 
de História, no mundo todo, a partir do século XX, uma aprendizagem insuficiente, em que inexistem elaborações de sentido na relação entre estudante e objeto de conhecimento e/ou a construção de uma intencionalidade geradora, arbitrária, que sustente o processo de aprendizagem. A produção acadêmica que marca o período recente — de meados dos anos 1960 às primeiras décadas do século XXI - forma um coro mais ou menos direcionado de vozes do processo, ou seja, permite construir um quadro sobre como, academicamente, se tem observado, percebido, constatado e manifestado em relação a todas estas tensões.

\section{Afinando o olhar: os percursos recentes do campo do Ensino de História no Brasil}

Seguindo nos passos da trajetória do campo, como mostra o esforço de Aryane Lima Costa e Margarida Maria Dias de Oliveira (2007), ao historiarem a construção do Ensino de História como objeto de pesquisa no Brasil, foi a partir dos anos 1970 que se deu mais espaço para discussões que transversalizavam e tematizavam o Ensino de História, como a formação de professores, o currículo e as práticas pedagógicas. O relato pessoal de experiências na sala de aula é, segundo Zamboni (2000/2001), a característica principal dos trabalhos produzidos sobre o Ensino de História nessa década. É a partir dos anos 1980 e ao longo dos 1990 que o Ensino de História é consolidado como um campo de pesquisa, inserido no contexto da redemocratização, sob novas concepções da relação entre educação, escola e sociedade, e vinculado a interesses como as esferas ideológica e política do ensino, os livros didáticos, o currículo, a formação de professores e as práticas docentes, que ainda hoje compõem boa parte das frentes de pesquisa identificadas por esse campo.

No estudo de Caimi (1999a; 2001), por meio da análise de 124 títulos de grande circulação entre os meios acadêmicos e escolares sobre o Ensino de História, entre 1980 e 1998, notou-se uma marca característica dos trabalhos publicados nessas duas décadas, que corrobora suas condições de produção. Durante a década de 1980, os trabalhos voltam-se à crítica dos diversos problemas do Ensino de História - muitos, novamente, provenientes das tensões entre escola e universidade e da própria dinâmica de mudanças epistemológicas e ampliação no campo da escrita da história e da historiografia brasileira. Já nos anos 1990 passam da crítica às diversas propostas - curriculares, de abordagens, de temas, de objetos, de recortes, que povoam o campo do Ensino de História. 
É aqui que vemos o Ensino de História afirmar-se e ampliar-se como campo de pesquisa. ${ }^{14}$ Mais recentemente, Evangelista e Triches (2006), Costa e Oliveira (2007) e Caimi (2008) buscaram sistematizar em diferentes direções alguns dados sobre o ensino de História como campo investigativo, no Brasil. Nos dois primeiros trabalhos, publicados em 2006 e 2007, respectivamente, as autoras buscaram, com base nas informações disponíveis para consulta digital pelo Diretório de Grupos de Pesquisa do Brasil, do Conselho Nacional de Desenvolvimento Científico e Tecnológico (CNPq), visualizar e analisar o desenvolvimento do campo por meio do crescimento de grupos de pesquisa (GPs) e linhas de pesquisa (LPs) distribuídas, como é comum, por programas de pós-graduação em Educação e em História das universidades brasileiras. Por sua vez, Caimi (2008) procura identificar, por meio de dados provenientes do portal da Capes (distribuição de cursos de mestrado acadêmico, profissional e doutorado no Brasil, em Educação e em História), dos anais dos Simpósios Nacionais de História da ANPUH (Associação Nacional de História), dos Encontros Nacionais Perspectivas do Ensino de História e dos Encontros Nacionais de Pesquisadores do Ensino de História, as principais "linhas de força" presentes na produção acadêmica sobre o Ensino de História. Um fenômeno percorre os três estudos: o surgimento de uma "linha de força" que vem ganhando espaço e procurando autonomia no campo do Ensino de História: trata-se da Didática da História, da qual deriva a Educação Histórica, compreendida como uma área de investigação interna à primeira e que se dedicaria justamente à "reflexão sobre a natureza do conhecimento histórico, tendo como objetivo apurar os sentidos que os indivíduos atribuem à História", por meio da aprendizagem histórica (SCHMIDT, CAINELLI, 2011, p. 11) ${ }^{15}$. Exemplos desse fenômeno são o aparecimento de grupos e linhas de pesquisa vinculados a pesquisadores “do Ensino de História” sob a denominação desses dois termos e da vinculação específica da Educação Histórica com os estudos sobre a aprendizagem histórica, sob um referencial teórico consistente e de forte presença tendo como base essencialmente a epistemologia da própria disciplina de referência, no caso, a

\footnotetext{
${ }^{14} \mathrm{O}$ artigo de Ernesta Zamboni, "Caminhos percorridos e outros... a descobrir e a percorrer" (História \& Ensino, v. 15, p. 39-50. Londrina, ago. 2009), apresenta uma síntese compreensiva sobre os percursos dos eventos ENPEH (Encontro de Pesquisadores do Ensino de História) e Encontro Nacional Perspectivas do Ensino de História, por meio dos quais é possível observar o crescimento do campo, desde 1988.

${ }^{15}$ No Brasil, há dois grupos de pesquisa que se destacam em relação à pesquisa em Educação Histórica, o Grupo Cultura, práticas escolares e Educação Histórica, da Universidade Federal do Paraná, divulgado por meio do LAPEDUH (Laboratório de Estudos em Educação Histórica), liderado pela Prof. ${ }^{a}$ Dr. ${ }^{a}$ Maria Auxiliadora Moreira dos Santos Schmidt, e o Grupo História e Ensino de História, da Universidade Estadual de Londrina, liderado pela Prof. ${ }^{a}$ Dr. ${ }^{a}$ Marlene Cainelli.
} 
História. O espaço que antes fazia-se pouco explorado e até mesmo lacunar (CAIMI, 1999a; 2001), hoje fervilha com um volume expressivo de produções.

Também em termos de diálogos internacionais se observam mudanças quanto a uma das observações de Caimi (1999a, p. 80) ao registrar o crescimento de mais de $100 \%$ de interlocuções com autores estrangeiros entre os trabalhos sobre Ensino de História produzidos no Brasil, comparativamente, entre as décadas de 1980 e 1990. Atualmente, é extremamente difícil que se encontre um trabalho que não possua interlocuções estrangeiras, que, ao longo dos anos e da ampliação progressiva do acesso a publicações tornaram-se base teórica matricial de todos os trabalhos do corpus.

Em dados de pesquisa expostos por Evangelista e Triches (2006), de acordo com a base de dados do Diretório de Grupos de Pesquisa do CNPq, em 2004, os números de grupos e linhas de pesquisa sob o título "Ensino de História", na área de Educação eram 51; na área de História, 11. Logo, se poderia inferir que a maior parte das investigações relacionadas ao ensino de história estava localizada, há mais de uma década, na área de Educação e, muito provavelmente, no interior de Programas de Pós-Graduação em Educação, afastados do campo da História. Em 2017, numa busca textual pelo mesmo Diretório, os seguintes dados foram encontrados: os grupos e linhas de pesquisa sob o título "Ensino de História" vinculados à área de Educação são 33. Sob a área de História, 53. Pode-se inferir, destarte, que uma das explicações para este segundo fenômeno esteja no observado anteriormente: a Didática da História, considerada uma subdisciplina da História disciplinar, ganha espaço também nos Programas de Pós-Graduação em História, fomentando linhas e grupos de pesquisa.

\section{Considerações finais}

É deste ambiente de proposições que tem derivado a maior parte dos estudos sobre Ensino de História no Brasil: de um ambiente multifacetado, permeado por relações complexas, por tensões entre a história como conhecimento produzido do passado, como valoração patriótica-moral, como instrumento de fazer-sentido cotidiano entre o passado, o presente e um futuro, de uma situação curricular fragilmente apoiada em soluções localizadas, sem o suporte de um currículo mínimo de referência - ou, a despeito da existência de um currículo prescrito, de práticas arraigadas em um núcleo duro, difícil de se transpor. Quem se atreve a preocupar-se com o ensino e a aprendizagem desse multifacetado objeto de saber enfrenta, mais do que entraves epistemológicos, 
verdadeiras disputas de espaço entre todas as representações de história e memória que povoam a cultura histórica, provenientes das mais diversas fontes.

Por ser um campo recente, sem tanta tradição, as grandes temáticas que acompanham há muito tempo as pesquisas educacionais - como a avaliação e a aprendizagem - ainda caminham lado-a-lado com questões operacionais e da prática docente, como inovações metodológicas e experimentações em sala de aula. Aproximarse desse campo, a partir de uma intenção investigativa, envolve o dever de conhecer as linhas já traçadas por investigações precedentes, bem como o seu espaço de ocupação no campo. Investigar "em” Ensino de História, desde um programa de pós-graduação em Educação, torna-se mais do que enfrentar um lugar de fronteira (MONTEIRO; PENNA, 2011), entre reconhecer as problemáticas do ensino e da aprendizagem como pertencentes a um interesse de um saber disciplinar específico, o da História, e compreender as transformações e exigências de práticas de ensino e aprendizagem comprometidas com os enfrentamentos do século XXI, que povoam os saberes da área da Educação. Torna-se a reinvindicação de um espaço físico, específico, em um campo investigativo, ao tomarse dele o que nele se tem produzido acerca dos problemas de ensinar e aprender História, no Brasil, no século XXI. Situa-se, desse modo, historicamente, o esforço de ensinar-se e aprender-se História em uma situação disciplinar e curricular localizada. Ainda, torna-se a tomada de posição acerca de questões incômodas, como a necessidade de redefinir-se a história escolar de forma que seja possível lidar com a realidade plurifacetada, multicultural, supra-identitária de forma produtiva, conciliando os níveis de estruturação de discursos históricos presentes em cada indivíduo, localizando-se e produzindo relevância em uma ordem social globalizada, em uma instituição herdeira do Estadonação, operando na pós-nacionalidade, em que transição e disputa de significados são constantes e afirmando-se em valores como a cidadania e o respeito às diferenças.

Em um cenário onde imperam extremos de representação identitária, em renovadas configurações, e perdem-se critérios de constituição de sentido do tempo (CARRETERO, 2010), como pode o Ensino de História produzir estratégias de aprendizagem propícias ao enfrentamento das constantes mudanças e demandas que esse mundo impõe?

Em síntese, toda e qualquer proposta interessada, hoje, pelo ensino e aprendizagem históricos enfrenta essa carga temporal, histórico-historiográfica, curricular e de práticas. Embora o discurso historiográfico e escolar sofra contínuas mudanças, se aproprie de outras fontes e situe-se em diferentes realidades, as marcas, os 
vestígios e os reminiscentes dos pesos paradigmáticos que informaram durante tanto tempo a produção do conhecimento histórico e, enviezadamente, a história escolar, não se dissipam facilmente, e operam em novas roupagens e mesmo claras presenças que podem emergir e encantar, a qualquer momento. Como sinaliza Monteiro (2007), o conhecimento histórico manejado em sala de aula pode compor duas principais versões de acabamento, de acordo com o modo como for mobilizado: pode libertar o olhar do estudante diante do mundo ou pode mantê-lo no mesmo lugar, legitimando os poderes constituídos e conservando o estado das coisas.

\section{Referências}

ABUD, Katia Maria. Formação da Alma e do Caráter Nacional: Ensino de História na Era Vargas. Revista Brasileira de História, vol.18, n.36, p.103-114, 1998. Disponível em: $<$ https://www.scielo.br/scielo.php?script=sci_arttext\&pid=S010201881998000200006\&lng=en\&nrm=iso\&tlng=pt>. Acesso em 16 out. 2020.

BANDECCHI, Brasil. História do Brasil. 3. ed. revista. São Paulo: Editôra Didática Irradiante, 1971.

CAIMI, Flávia Eloisa. Tendências e perspectivas do ensino da história: um estudo historiográfico sobre a produção acadêmica e escolar (1980-1998). Dissertação (Mestrado em Educação). Universidade de Passo Fundo, Passo Fundo, 1999a.

O livro didático: algumas questões. In: DIEHL, Astor Antônio. (Org.) O livro didático e o currículo de história em transição. Passo Fundo: Ediupf, 1999b. p. 23-109.

Conversas e controvérsias: o ensino de história no Brasil (1980-1998). Passo Fundo: Ed. Universidade de Passo Fundo, 2001.

Novas conversas e antigas controvérsias: um olhar sobre a historiografia do ensino de história. In: OLIVEIRA; Margarida Maria Dias; CAINELLI, Marlene Rosa; OLIVEIRA, Almir Félix Batista de. (Org.). Ensino de História: múltiplos ensinos em múltiplos espaços. Natal/RN: Editora da UFRN, 2008. p. 127-135.

; MISTURA, Letícia. Investigar em Ensino de História: entre fronteiras e limites epistemológicos. In: MONTEIRO, Ana Maria Monteiro; RALEJO, Adriana. (Orgs.). Cartografias da Pesquisa em Ensino de História. 1.ed. Rio de Janeiro: Mauad, v. 1, p. 187-198, 2019.

CAINELLI, Marlene; SCHMIDT, Maria Auxiliadora (Orgs.). Educação Histórica: teoria e pesquisa. Ijuí: Editora Unijuí, 2011.

CARRETERO, Mario. Documentos de identidade: a construção da memória histórica em um mundo globalizado. Porto Alegre: Artmed, 2010. 
CERRI, Luis Fernando. Didática da história: uma geografia do saber histórico nas sociedades. In: NETO; José Miguel Arias. (Org.). Dez Anos de Pesquisas em ensino de História: VI Encontro Nacional de Pesquisadores de Ensino de História. 1.ed. Londrina, PR: Atrito Art Editorial, v. 1, p. 136-144, 2005.

CHARTIER, Roger. A mão do autor e a mente do editor. São Paulo: Editora Unesp, 2014.

COSTA, Aryana Lima; OLIVEIRA, Margarida Maria Dias de. O ensino de história como objeto de pesquisa no Brasil: no aniversário de 50 anos da área de pesquisa, notícias do que virá. Sceculum: Revista de História, João Pessoa, v. 16, p. 147-160, jan./jun. 2007. Disponível em: <https://periodicos.ufpb.br/ojs2/index.php/srh/article/view/11378>. Acesso em: 16/10/2020.

COSTA, Emília Viotti da. Os objetivos do ensino da História no curso secundário. Revista de História (USP), v. 14, n. 29, p. 117-120, jan./mar. 1957. Disponível em: <https://doi.org/10.11606/issn.2316-9141.rh.1957.105130>. Acesso em: 16/10/2020.

DIEHL, Astor Antônio. A cultura historiográfica brasileira: do IHGB aos anos 1930. Passo Fundo: EDIUPF, 1998.

DORIA, Escragnolle. Memória histórica do Colégio de Pedro Segundo (1837-1937). 2.ed. Brasília: INEP, 1997

EVANGELISTA, Olinda; TRICHES, Jocemara. Ensino de História, Didática de História, Educação Histórica: alguns dados de pesquisa (2000-2005). Educar em Revista, n. Especial, p. 33-55, Curitiba: 2006. Disponível em: < https://periodicos.ufpb.br/ojs/index.php/srh/article/view/11378/6492>. Acesso em: 16/10/2020.

FONSECA, Selva Guimarães. Ensino de História: diversificação de abordagens. Revista Brasileira de História, v. 9, n. 19, p. 197-209. São Paulo, set. 1989/fev. 1990. Disponível em: <https://www.anpuh.org/arquivo/download?ID_ARQUIVO=3885>. Acesso em: $16 / 10 / 2020$.

FONSECA, Thaís Nívia de Lima e. História \& ensino de História. Belo Horizonte: Autêntica, 2003.

FREITAS, Itamar. A pedagogia da história de Jonathas Serrano para o ensino secundário brasileiro (1913-1935). Tese (Doutorado em Educação). Pontifícia Universidade Católica de São Paulo, São Paulo, SP, 2006. Disponível em: < https://tede2.pucsp.br/bitstream/handle/10556/1/Itamar\%20Freitas.pdf >. Acesso em: $16 / 10 / 2020$.

GARCIA, Rozendo Sampaio; CARONE, Maxim T. História do Brasil: primeiro volume: destinado à $3^{a}$ série do curso ginasial. São Paulo: Editôra do Brasil, 1946.

HALBWACHS, Maurice. A memória coletiva. São Paulo: Centauro, 2006. 
HOLLANDA, Guy de. Um quarto de século de programas e compêndios de História para o ensino secundário brasileiro (1931-1956). Rio de Janeiro: Instituto Nacional de Estudos Pedagógicos, 1957.

LAVILLE, Christian. A guerra das narrativas: debates e ilusões em torno do ensino de História. Revista Brasileira de História, São Paulo, v. 19, n. 38, p. 125-138, 1999. Disponível em: $\quad$ https://www.scielo.br/scielo.php?script=sci_arttext\&pid=S010201881999000200006>. Acesso em: 16/10/2020.

LOBO, R. Haddock. História do Brasil. São Paulo: Livraria Duas Cidades, 1967.

LUNA, Sérgio Vasconcelos. Planejamento de pesquisa: uma introdução: elementos para uma análise metodológica. 2. ed. São Paulo: Ed. Pontifícia Universidade Católica de São Paulo, 2009.

MENDES, Murilo. A história no curso secundário: monografia para o concurso da cadeira de Metodologia do Ensino Secundário do Instituto de Educação da Universidade de São Paulo. São Paulo: Gráfica Paulista/João Bentivegna, 1935.

MONTEIRO, Ana Maria. Ensino de história: entre história e memória. In: Silva, Gilvan Ventura, Regina Helena Silva e Simões, Sebastião Pimentel Franco (Org.). História e Educação: territórios em convergência. Vitória (ES): GM/PPGHIS/UFES, 2007.

; PENNA, Fernando de Araujo. Ensino de História: saberes em lugar de fronteira. Educação \& Realidade, v. 36 n. 1, p. 191-211, jan./abr. 2011. Disponível em: $<$ https://seer.ufrgs.br/educacaoerealidade/article/view/15080>. Acesso em: 16/10/2020.

NADAI, Elza. O ensino de História no Brasil: trajetória e perspectiva. Revista Brasileira de História, v. 13, n. 25/26, p. 143-162. São Paulo, set. 1992/ago. 1993. Disponível em: <https://www.anpuh.org/arquivo/download?ID_ARQUIVO=30596>. Acesso em: $16 / 10 / 2020$.

PROST, Antoine. Doze lições sobre a história. 2. ed. 3. reimp. Belo Horizonte: Autêntica Editora, 2015.

RIBEIRO, João. História do Brasil: curso superior: segundo os programmas do Collegio Pedro II. 13. ed. Rio de Janeiro: Livraria Francisco Alves, 1935.

SERRANO, Jonathas. Como se ensina a história. São Paulo: Melhoramentos, 1935.

SILVA, Marcos Antônio; FONSECA, Selva Guimarães. Ensino de História hoje: errâncias, conquistas e perdas. Revista Brasileira de História, v. 31, n. 60, p. 13-33, São Paulo, 2010. Disponível em: < https://www.scielo.br/pdf/rbh/v30n60/a02v3060.pdf >. Acesso em: 16/10/2020.

TAPAJÓS, Vicente. História do Brasil. 6. ed. São Paulo: Companhia Editora Nacional, 1954.

WEHLING, Arno. A invenção da história: estudos sobre o historicismo. 2.ed. Rio de Janeiro: Gama Filho, 2001. 
DOI: 10.47694/issn.2674-7758.v2.i5.2020.92116

ZAMBONI, Ernesta. Caminhos percorridos e outros... a descobrir e a percorrer. História \& Ensino, Londrina, v. 15, p. 39-50, ago. 2009. Disponível em: < http://www.uel.br/revistas/uel/index.php/histensino/article/view/11427>. Acesso em: 16/10/2020.

Panorama das pesquisas no ensino de História. Saculum: Revista de História, n. 6/7, p.105-117, jan./dez. 2000-2001. Disponível em: https://moodle.ufsc.br/pluginfile.php/834355/mod_resource/content/1/Zamboni\%20\%20Saeculum.pdf >. Acesso em: 16 out. 2020. 
DOI: 10.47694/issn.2674-7758.v2.i5.2020.92116 